\title{
Efeito da adubação com boro e esterco bovino sobre a produtividade da figueira e as pro- priedades químicas do solo
}

\author{
Effect of boron and cattle manure fertilization on yield productivity fig tree and on soil properties
}

\author{
Luiz Carlos Santos Caetano ${ }^{1}$ Almy Junior Cordeiro de Carvalho ${ }^{2}$
}

\section{RESUMO}

O objetivo deste trabalho foi verificar o efeito da adubação da cultura da figueira com boro e esterco bovino sobre a produtividade de figos verdes e as propriedades químicas do solo. Os tratamentos foram cinco doses de ácido bórico (0, 20, 40, 60 e $100 \mathrm{~g} \mathrm{planta}^{-1}$ ) combinadas com dois níveis de adubação de esterco (sem esterco e $10 \mathrm{~kg}$ de esterco/planta). $O$ delineamento experimental foi o de blocos casualizados em esquema de parcelas subdivididas e quatro repetições. A adubação com ácido bórico não afetou a produtividade de figos, enquanto que o esterco bovino aumentou-a. Os teores de fósforo e potássio no solo aumentaram significativamente e o teor de alumínio diminuiu significativamente em função da adubação com esterco bovino. O teor de B no solo, extraído pelo método da água quente, aumentou linearmente em função das doses de ácido bórico.

Palavras-chave: Ficus carica L., adubação orgânica, ácido bórico, propriedades químicas do solo.

\section{ABSTRACT}

The objective of the present work was evaluate the effect of fig tree orchard fertilization with boron and cattle manure on the green fig yield and soil chemical properties. The treatments were five boric acid levels (0, 20, 40, 60 and $100 \mathrm{~g} \mathrm{plant}^{-1}$ ) combined with two cattle manure fertilization levels (without cattle manure and $10 \mathrm{~kg}$ of cattle manure/plant). The experimental design was that of randomized blocks in a split-plot scheme and four repetitions. The boric acid fertilization did not affect the fig productivity whereas the cattle manure one increased it. The $P$ and $K$ content increased significantly and the Al content decreased significantly in function of the cattle manure fertilization. The B soil content, extracted by hot water methodology increased linearly in function of the boric acid levels.
Key words: Ficus carica L., organic fertilization, boric acid, soil chemical properties.

\section{INTRODUÇÃO}

A adubação com esterco é amplamente recomendada para o cultivo da figueira. CAMPODALL'ORTO et al. (1996) recomendam para a figueira adubação com $10 \mathrm{~kg}$ de esterco de curral bem curtido por cova, por ocasião do plantio, e a mesma quantidade por planta anualmente como adubação de produção. Dos benefícios da utilização da adubação orgânica na cultura da figueira, a melhoria das propriedades físicas do solo, o fornecimento de nutrientes e o aumento da população de organismos nematófagos do solo podem ser considerados os mais importantes.

No solo, o aumento do teor de matéria orgânica causa, entre outros efeitos, o aumento do $\mathrm{pH}$ e da saturação por bases, assim como a complexação e a precipitação do alumínio da solução do solo (FRANCHINI et al., 1999, MELLO \& VITTI, 2002).

O boro está relacionado a muitos processos fisiológicos da planta, que são afetados pela sua deficiência, como o transporte de açúcares, a síntese da parede celular, a lignificação, a estrutura da parede celular, o metabolismo de carboidratos, o metabolismo de RNA, a respiração, o metabolismo de AIA, o metabolismo fenólico, o metabolismo de ascorbato e a integridade da membrana plasmática (CAKMAC \& RÖMHELD, 1997).

${ }^{1}$ Instituto Capixaba de Pesquisa, Assistência Técnica e Extensão Rural, CRDR Sul-Caparaó, Rua Dom Fernando, 39, Bairro Independência, 29306-350, Cachoeiro de Itapemirim, ES, Brasil. E-mail: luizcaetano@incaper.es.gov.br. Autor para correspondência.

${ }^{2}$ Setor de Horticultura, Universidade Estadual do Norte Fluminense (UENF), Campos dos Goytacazes, RJ, Brasil. 
O boro disponível no solo encontra-se principalmente associado à matéria orgânica, portanto tende a apresentar maior concentração nos horizontes superficiais do solo. A absorção de boro pelas plantas ocorre na forma de ácido bórico não dissociado e é proporcional à concentração do elemento na solução do solo (GOLDBERG, 1997).

O manejo da adubação com boro deve ser cuidadoso, pois a faixa entre deficiência e toxidez de boro é mais estreita do que para qualquer outro elemento nutriente (NOBLE et al., 1993, GOLDBERG,1997; QUAGGIO\& PIZAJR., 2001). Porém, deve ser observado o teor de boro disponível correspondente à dose fornecida do nutriente, já que a concentração de B na solução do solo é geralmente controlada pelas reações de adsorção do boro.

O objetivo deste trabalho foi verificar o efeito da adubação com boro e esterco bovino sobre a produtividade de figos verdes da figueira e as propriedades químicas do solo.

\section{MATERIAL E MÉTODOS}

O experimento foi conduzido entre novembro de 2003 e abril de 2004, em área experimental pertencente à Universidade Estadual do Norte Fluminense Darcy Ribeiro (UENF), localizada no Colégio Agrícola Antônio Sarlo, município de Campos dos Goytacazes, RJ (a 2119'23" de latitude sul e $41^{\circ} 19^{\prime} 40^{\prime \prime}$ de longitude Oeste), em solo tipo Latossolo Amarelo distrófico. O pomar era formado por figueiras de dois anos de idade do cultivar "Roxo de Valinhos", conduzidas com doze ramos produtivos e plantadas no espaçamento 3 x 2m.

Foram retiradas amostras de solo da área experimental utilizando-se um amostrador tipo sonda com uma amostra por unidade experimental e profundidade de amostragem. Estas amostras foram homogeneizadas, retirando-se, a seguir, uma amostra por profundidade para envio ao laboratório de análise de solo. Os resultados das análises química e física das amostras de solo da área experimental são apresentados na tabela 1 .

Posteriormente à amostragem do solo e cerca de trinta dias antes da implementação dos tratamentos, toda a área experimental recebeu aplicação a lanço sobre a superfície do solo de calcário dolomítico (PRNT 80\%), na proporção de $1.300 \mathrm{~kg} \mathrm{ha}^{-1}$. Em razão da aplicação do calcário apenas na superfície do solo, a quantidade de calcário foi determinada tomando-se como base os resultados da camada de 0 a $10 \mathrm{~cm}$ de profundidade e o cálculo feito utilizando a fórmula $\left[\mathrm{Al}^{3+} \mathrm{x} 2\right]+[2-\mathrm{Ca}+\mathrm{Mg}]$ $=\mathrm{tha}^{-1}$ de $\mathrm{CaCO}_{3}$, como recomendado no Manual de Adubação para o Estado do Rio de Janeiro (FREIRE \& ALMEIDA, 1988).

Ao final do experimento, utilizando-se um amostrador tipo sonda, foram retiradas amostras de solo na profundidade de 0 a $20 \mathrm{~cm}$ de todas as unidades experimentais para verificar o efeito dos tratamentos nas propriedades químicas do solo. A amostragem foi feita na área de projeção da copa das plantas úteis, em dois pontos por planta, totalizando quatro subamostras por unidade experimental. As subamostras foram homogeneizadas, retirando-se, a seguir, uma amostra para cada unidade experimental para envio ao laboratório de análise de solo.

As parcelas experimentais foram compostas por quatro plantas em linha, sendo úteis as duas plantas centrais. Entre cada linha com plantas úteis, havia uma linha de plantas que constituíam bordaduras, assim como as duas linhas marginais da área experimental.

Os tratamentos consistiram de cinco doses de ácido bórico (0, 20, 40, 60 e 100g planta $\left.{ }^{-1}\right)$, combinadas com dois níveis de esterco bovino curtido (sem esterco ou com $10 \mathrm{~kg}$ de esterco bovino por planta). O delineamento experimental utilizado foi o de blocos ao

Tabela 1 - Análise química e física do solo.

\begin{tabular}{|c|c|c|c|c|c|c|c|c|c|c|c|c|c|c|}
\hline Prof. & $\mathrm{pH}$ & $\mathrm{P}$ & $\mathrm{K}$ & $\mathrm{Ca}$ & $\mathrm{Mg}$ & $\mathrm{Al}$ & $\mathrm{H}+\mathrm{Al}$ & $\mathrm{Na}$ & \multicolumn{2}{|c|}{$\mathrm{C}$} & SB & $\mathrm{T}$ & $\mathrm{t}$ & $\mathrm{m}$ \\
\hline $\mathrm{cm}$ & & $\mathrm{mgdm}^{-3}$ & \multicolumn{6}{|c|}{ 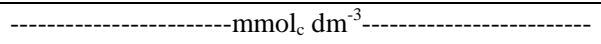 } & \multicolumn{2}{|c|}{$\mathrm{g} \mathrm{dm}^{-3}$} & \multicolumn{3}{|c|}{-----mmol $\mathrm{dm}^{-3}----$} & $\%$ \\
\hline $0-10$ & 4,5 & 19 & 2,1 & 15 & 10 & 5 & 66 & 0,6 & \multicolumn{2}{|c|}{15,6} & 28 & 94 & 33 & 15 \\
\hline $10-20$ & 4,2 & 16 & 1,9 & 14 & 8 & 9 & 62 & 0,7 & \multicolumn{2}{|c|}{14,1} & 25 & 87 & 34 & 27 \\
\hline $20-40$ & 4,1 & 17 & 1,2 & 14 & 8 & 10 & 59 & 0,3 & \multicolumn{2}{|c|}{9,6} & 24 & 83 & 34 & 30 \\
\hline & & & & & & & & & \multicolumn{6}{|c|}{ Granulometria } \\
\hline Prof. & $\mathrm{V}$ & $\mathrm{Fe}$ & $\mathrm{Cu}$ & $\mathrm{Zn}$ & & & $\mathrm{S}$ & $\mathrm{B}$ & \multicolumn{4}{|c|}{ Areias (\%) } & Silte & Argila \\
\hline $\mathrm{cm}$ & $\%$ & \multicolumn{7}{|c|}{ 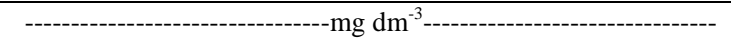 } & G & $\mathrm{M}$ & $\mathrm{F}$ & Total & \multicolumn{2}{|c|}{---------\%-------- } \\
\hline $0-10$ & 30 & 60 & 1,2 & 2,0 & & & 26,5 & 0,29 & 10 & 0 & 41 & 51 & 8 & 41 \\
\hline $10-20$ & 28 & 64 & 0,8 & 1,5 & & & 35,3 & 0,29 & 12 & 17 & 22 & 51 & 7 & 42 \\
\hline $20-40$ & 29 & 54 & 0,4 & 1,0 & & & 43,9 & 0,22 & 12 & 10 & 26 & 48 & 6 & 46 \\
\hline
\end{tabular}


acaso com quatro repetições, em esquema de parcelas subdivididas, nas quais os níveis de esterco compunham as parcelas e as doses de boro as subparcelas.

Os frutos foram colhidos no ponto adequado para industrialização do fruto verde, ou seja, no máximo crescimento, com coloração da casca verde intenso e partes internas com coloração branca. Para determinação do teor de boro na matéria seca foliar, foram realizadas duas amostragens, em 27/01 e 10/03/ 2004. Foram coletadas folhas recém-maduras e totalmente expandidas (QUAGGIO et al., 1996).

As doses de boro foram divididas em três parcelas tendo sido aplicadas em dezembro/2003 (1/4), janeiro/2004 (1/2) e fevereiro/2004 (1/4). As adubações com esterco bovino foram realizadas numa única vez, em dezembro/2003. Tanto o esterco quanto o ácido bórico foram colocados a uma distância aproximada de $40 \mathrm{~cm}$ do tronco da planta (área de projeção da copa das plantas).

O esterco bovino utilizado apresentava as seguintes propriedades químicas: $\mathrm{pH}$ em $\mathrm{H}_{2} \mathrm{O}=8,1$; Umidade $=37 \% ; \mathrm{N}=14,2 \mathrm{~g} \mathrm{~kg}^{-1} ; \mathrm{P}=3,7 \mathrm{~g} \mathrm{~kg}^{-1} ; \mathrm{K}=12,1 \mathrm{~g}$ $\mathrm{kg}^{-1} ; \mathrm{Ca}=7,2 \mathrm{~g} \mathrm{~kg}^{-1} ; \mathrm{Mg}=5 \mathrm{~g} \mathrm{~kg}^{-1} ; \mathrm{C}=173 \mathrm{~g} \mathrm{~kg}^{-1} ; \mathrm{S}=$ $2,05 \mathrm{~g} \mathrm{~kg}^{-1} ; \mathrm{Cl}=6,25 \mathrm{~g} \mathrm{~kg}^{-1} ; \mathrm{Na}=0,83 \mathrm{~g} \mathrm{~kg}^{-1} ; \mathrm{Fe}=11.000 \mathrm{mg}$ $\mathrm{kg}^{-1} ; \mathrm{Cu}=16 \mathrm{mg} \mathrm{kg}^{-1} ; \mathrm{Zn}=62 \mathrm{mg} \mathrm{kg}^{-1} ; \mathrm{Mn}=235 \mathrm{mg} \mathrm{kg}^{-1}$; $\mathrm{B}=14,5 \mathrm{mg} \mathrm{kg}^{-1}$. Todas as plantas receberam ainda adubações com nitrogênio (120g de $\mathrm{N}_{\text {planta }}{ }^{-1}$ ) e potássio (80g de $\mathrm{N}$ planta $\left.{ }^{-1}\right)$. A área experimental recebeu ainda irrigação suplementar.

Os extratores utilizados na análise das amostras de solo foram: para P, Na, K, Fe, Zn, Mn e Cu, Mehlich 1; para Ca, Mg e Al, $\mathrm{KCl} 1 \mathrm{~mol} \mathrm{~L}^{-1}$; para $\mathrm{H}+\mathrm{Al}$, acetato de cálcio $0,5 \mathrm{~mol} \mathrm{~L}^{-1}$, $\mathrm{pH}$ 7,0; para $\mathrm{B}$, água quente; para S, fosfato monocálcico.

Os resultados foram submetidos à análise de variância e regressão e as médias foram testadas utilizando teste de Tukey a 5\% de probabilidade de erro.

\section{RESULTADOS E DISCUSSÃO}

Verificou-se que as variáveis produtividade, peso médio de frutos e número de frutos por planta não foram influenciadas pelas doses de boro, havendo efeito somente dos níveis de esterco (Tabela 2). A produtividade é diretamente influenciada pelo peso médio e pelo número de frutos. Provavelmente, a maior produtividade das parcelas que receberam esterco deveu-se às melhorias das condições do solo, sobretudo de fertilidade pelo fornecimento adicional de nutrientes pelo esterco bovino. BORGES et al. (2002) verificaram que a adubação da bananeira da terra com 20L de esterco bovino em cobertura aumentou o número de frutos por cacho e o comprimento médio do fruto em relação à adubação química.

Os valores de $\mathrm{pH}$ e os teores de $\mathrm{S}$ não foram influenciados pelos níveis de esterco, já os teores de fósforo e potássio no solo aumentaram significativamente com a adubação com esterco (Tabela 3).

Os teores de Ca e Mg não foram influenciados pela adubação com esterco (Tabela 3).

$\mathrm{O}$ teor de alumínio foi reduzido significativamente pela adubação com esterco (Tabela 3). De acordo com LOPES \& ABREU (1987), o teor de $6,53 \mathrm{mmol} \mathrm{dm}^{-3}$ nas parcelas onde não se aplicou esterco é considerado médio e o teor de $3,24 \mathrm{mmol}_{c} \mathrm{dm}^{-3}$ nas parcelas com esterco, baixo. A redução dos níveis de Al após a aplicação de resíduos vegetais e esterco de animais descrita em vários estudos (OLIVEIRA FILHO et al., 1987; MIYAZAWA et al., 1993; FRANCHINI et al., 1999) pode ocorrer por hidrólise, devido à

Tabela 2 - Produtividade, peso médio e número de frutos da figueira em função de adubação com boro e esterco bovino.

\begin{tabular}{|c|c|c|c|c|c|c|c|c|c|}
\hline \multirow{2}{*}{$\mathrm{B}\left(\right.$ g planta $\left.^{-1}\right)$} & \multicolumn{3}{|c|}{ Produtividade $\left(\mathrm{kg} \mathrm{ha}^{-1}\right)$} & \multicolumn{3}{|c|}{ Peso médio de frutos(g) } & \multicolumn{3}{|c|}{ Número de frutos/planta } \\
\hline & $\begin{array}{c}\text { Com } \\
\text { esterco }\end{array}$ & $\begin{array}{c}\text { Sem } \\
\text { esterco }\end{array}$ & Média & $\begin{array}{c}\text { Com } \\
\text { esterco }\end{array}$ & $\begin{array}{c}\text { Sem } \\
\text { esterco }\end{array}$ & Média & $\begin{array}{c}\text { Com } \\
\text { esterco }\end{array}$ & $\begin{array}{c}\text { Sem } \\
\text { esterco }\end{array}$ & Média \\
\hline 0 & 7680 & 7914 & 7797 & 13,5 & 13,2 & 13,4 & 317 & 356 & 336 \\
\hline 20 & 7041 & 5957 & 6499 & 13,8 & 13,2 & 13,5 & 307 & 269 & 288 \\
\hline 40 & 8058 & 6443 & 7250 & 13,9 & 12,8 & 13,4 & 346 & 298 & 322 \\
\hline 60 & 6885 & 6573 & 6729 & 13,5 & 13,1 & 13,3 & 308 & 291 & 299 \\
\hline 100 & 7921 & 6096 & 7008 & 14,1 & 12,7 & 13,4 & 391 & 281 & 336 \\
\hline Média & $7517 a$ & $6597 b$ & 7057 & 13,9 a & $13,0 \mathrm{~b}$ & 13,4 & $334 \mathrm{a}$ & 299 b & 316 \\
\hline \multicolumn{2}{|c|}{ CV parcela (\%) } & \multicolumn{2}{|l|}{4,1} & & \multicolumn{2}{|l|}{1,79} & \multicolumn{3}{|c|}{3,06} \\
\hline \multicolumn{2}{|c|}{ CV subparcela (\%) } & \multicolumn{2}{|l|}{15,8} & & \multicolumn{2}{|l|}{4,84} & \multicolumn{3}{|c|}{14,6} \\
\hline
\end{tabular}

Médias seguidas pela mesma letra na linha não diferem entre si pelo teste de Tukey ao nível de 5\% de probabilidade. 
Tabela 3 - Propriedades químicas do solo em função da aplicação do esterco bovino.

\begin{tabular}{|c|c|c|c|c|c|c|c|c|}
\hline Esterco bovino & $\mathrm{pH}$ & $\mathrm{S}$ & $\mathrm{P}$ & K & $\mathrm{Ca}$ & $\mathrm{Mg}$ & $\mathrm{Al}$ & CTC \\
\hline kg planta $^{-1}$ & & \multicolumn{2}{|c|}{------------mg dm ${ }^{-3}----------$} & --------. & -------- & $-\mathrm{mmol}_{\mathrm{c}}$ & --------------. & --------- \\
\hline 0 & $4,68 \mathrm{a}$ & $17,1 \mathrm{a}$ & 5,85 b & $2,13 \mathrm{~b}$ & 15,9 a & $8,7 \mathrm{a}$ & $6,53 \mathrm{a}$ & 72,0 a \\
\hline 10 & $4,98 \mathrm{a}$ & $18,3 \mathrm{a}$ & $10,40 \mathrm{a}$ & 3,03 a & $17,1 \mathrm{a}$ & 9,5 a & $3,24 \mathrm{~b}$ & $72,7 \mathrm{a}$ \\
\hline CV (\%) & 4,4 & 14,2 & 24,4 & 8,6 & 15,4 & 8,9 & 20,7 & 3,4 \\
\hline Esterco bovino & $\mathrm{Fe}$ & $\mathrm{Cu}$ & $\mathrm{Zn}$ & $\mathrm{Mn}$ & $\mathrm{B}$ & $\mathrm{C}$ & $\mathrm{H}+\mathrm{Al}$ & $\mathrm{V}$ \\
\hline kg planta $^{-1}$ & \multicolumn{5}{|c|}{----------------------------------------------mg dm ${ }^{-3}$-------------------------------------- } & $\mathrm{g} \mathrm{dm}^{-3}$ & $\mathrm{mmol}_{\mathrm{C}} \mathrm{dm}^{-3}$ & $\%$ \\
\hline 0 & $63,9 \mathrm{a}$ & $0,38 \mathrm{a}$ & $0,94 \mathrm{a}$ & $4,77 \mathrm{a}$ & $1,18 \mathrm{a}$ & 16,5 a & $45 \mathrm{a}$ & $37,7 \mathrm{a}$ \\
\hline 10 & $47,6 \mathrm{a}$ & $0,32 \mathrm{a}$ & $1,37 \mathrm{a}$ & 5,95 a & $1,13 \mathrm{a}$ & $17,2 \mathrm{a}$ & $43 \mathrm{a}$ & $41,7 \mathrm{a}$ \\
\hline CV (\%) & 22,0 & 13,2 & 19,0 & 13,8 & 19,8 & 4,2 & 9,1 & 12,0 \\
\hline
\end{tabular}

Médias seguidas pela mesma letra na coluna não diferem pelo teste de Tukey ao nível de 5\% de probabilidade.

complexação por ácidos orgânicos liberados por estes materiais (MIYAZAWA et al., 2000).

Os valores médios de CTC e os teores de micronutrientes e carbono não apresentaram efeito significativo das doses de esterco, assim como os valores de $(\mathrm{H}+\mathrm{Al})$ e de saturação em bases (V) (Tabela 3).

Entre as caraterísticas químicas do solo afetadas pela matéria orgânica, destacam-se a disponibilidade de nutrientes para as culturas, a capacidade de troca de cátions e a complexação do $\mathrm{Al}^{3+}$ e do $\mathrm{Fe}^{2+} / \mathrm{Fe}^{3+}$ (BAYER \& MIELNICZUK, 1999; MIYAZAWA et al., 2000). A matéria orgânica do solo apresenta carga elétrica negativa predominante, podendo por isso ser considerada como um aniônio orgânico, e combina-se com o $\mathrm{Al}^{3+}$ e $\mathrm{Fe}^{2+} / \mathrm{Fe}^{3+}$ imobilizando o ferro e o alumínio de tal modo que esses elementos não podem nessa forma precipitar o $\mathrm{H}_{2} \mathrm{PO}_{4}^{-}$, aumentando a disponibilidade do $\mathrm{P}$ existente no solo (CANELLAS et al., 1999).

As variações edafoclimáticas e o tipo e origem do material utilizado como adubo orgânico podem influenciar as propriedades químicas do solo, uma vez que MELLO \& VITTI (2002), trabalhando em um argissolo vermelho-amarelo, A moderado, textura arenosa/média, cultivado com tomateiro no município de Piracicaba, SP, não encontraram influência nos teores de $\mathrm{P}$ e $\mathrm{K}$ no solo, assim como para $\mathrm{pH}, \mathrm{C}$, Ca, $\mathrm{Mg}, \mathrm{H}+\mathrm{Al}$ e CTC com adubações de até $14 \mathrm{tha}^{-1}$ de lodo de cervejaria + cavaco de eucalipto, de $16 \mathrm{t} \mathrm{ha}^{-1} \mathrm{de}$ composto de lixo ou de $6 \mathrm{t} \mathrm{ha}^{-1}$ de cama de frango. HOLANDA et al. (1982) constataram que a adição de $12 \mathrm{t} \mathrm{ha}^{-1}$ de esterco de galinha não aumentou o pH e os teores de $\mathrm{Ca}$ e $\mathrm{K}$ do solo em quatro seqüências de culturas em solo de encosta basáltica no Estado do Rio Grande do Sul.

Da análise de regressão, ajustaram-se modelos significativos para os teores disponíveis de boro no solo para ambos os níveis de esterco em função das doses de ácido bórico adicionadas, observandose que, com o aumento das doses de ácido bórico adicionadas ao solo, houve aumento nos teores de $\mathrm{B}$ disponível (Figura 1). Mesmo comportamento foi observado para o teor foliar de boro em função das doses de ácido bórico, independentemente da época de amostragem $\left(\mathrm{Y}=0,731^{* *} \mathrm{x}+52,1, \mathrm{R}^{2}=0,99\right)$. Resultado semelhante foi obtido por QUAGGIO \& PIZA JR. (2001) em trabalho conduzido com laranja-pêra, no qual a aplicação de doses crescentes de B no solo foi acompanhada pelo aumento linear e crescente nos teores do elemento tanto no solo, extraído pelo método da água quente, como nas folhas. No cafeeiro, trabalho conduzido por CORREA et al. (1985) mostra que a absorção de $\mathrm{B}$ foi proporcional ao teor de $\mathrm{B}$ em equilíbrio na solução do solo.

Para os demais nutrientes e propriedades químicas do solo não foram encontrados efeitos das doses de ácido bórico. A interação doses de ácido bórico e níveis de esterco não foi significativa. NAKAYAMA (1989), variando doses de B de 0 a 0,50 $\mathrm{mg} \mathrm{kg}^{-1}$ para mudas de cacaueiro cultivadas em vaso com solo retirado da camada de 0 a $20 \mathrm{~cm}$ de um Ultisol distrófico com textura argilo-siltosa, não encontrou qualquer influência sobre o $\mathrm{pH}$ do solo e sobre os teores de $\mathrm{Al}, \mathrm{Ca}, \mathrm{Mg}, \mathrm{K}$ e P, porém o autor não determinou o teor de boro e dos demais micronutrientes.

A toxidez de B está associada à aplicação de doses maiores do que $3 \mathrm{~kg}$ de $\mathrm{B}$ por hectare de uma só vez ou muito localizada ao redor das plantas, sendo que, em pomares cítricos recém-plantados, a dose de $2 \mathrm{~kg} \mathrm{ha} \mathrm{k}^{-1}$ foi suficiente para provocar a toxidez. A reversão dos sintomas ocorre mais rapidamente com a elevação do pH do solo, através da calagem, e também por lavagem do excesso de B pela lixiviação (QUAGGIO 


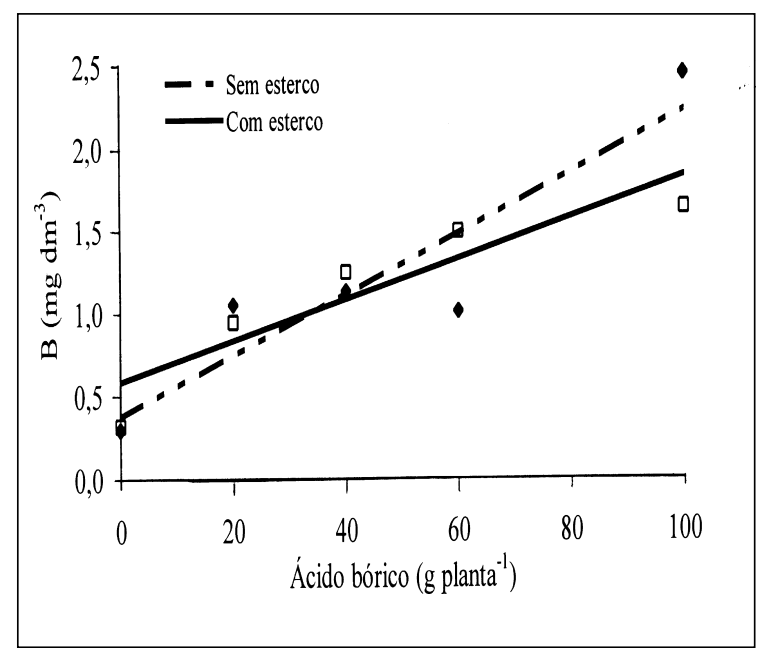

Figura 1 - Teores de B no solo, extraído pelo método de água quente, sem aplicação de esterco bovino ( $\mathrm{Y}=$ $\left.0,0185^{*} \mathrm{x}+0,372, \mathrm{R}^{2}=0,85\right)$ e com aplicação de esterco bovino ( $\left.\mathrm{Y}=0,0124 * \mathrm{x}+0,586, \mathrm{R}^{2}=0,84\right)$, em função de doses de ácido bórico.

\& PIZA JR 2001). NOBLE et al. (1993), estudando o efeito do B em alfafa cultivada em vasos, não encontraram qualquer efeito prejudicial com dose máxima de 2,24kg ha-1 . NAKAYAMA (1989) utilizou doses de até $1 \mathrm{~kg} \mathrm{ha}^{-1}$ sem prejuízos a mudas do cacaueiro crescidas em vasos. Para mudas de limãocravo, doses de $\mathrm{B}$ de até $6 \mathrm{~kg} \mathrm{ha}^{-1}$ não foram fitotóxicas (YAMADA, 2001). Talvez a grande deficiência desses trabalhos seja a falta de correlação entre as doses de B aplicadas no solo e a disponibilidade do elemento para as plantas, uma vez que os teores de boro no solo não foram determinados. Neste experimento, na dose máxima de $100 \mathrm{~g}$ de ácido bórico por planta, correspondente a 166,6kg de ácido bórico ou a 29,1kg de $\mathrm{B}$ por hectare, foi encontrado um teor médio de boro disponível no solo, extraído pelo método de água quente, de $1,15 \mathrm{mg} \mathrm{dm}^{-3}$, variando de cerca de $0,30 \mathrm{mg}$ $\mathrm{dm}^{-3}$ a 2,03mg dm${ }^{-3}$, respectivamente, na doze zero e com aplicação de $100 \mathrm{~g}$ de ácido bórico por planta. Com esses teores no solo não foi constatada influência sobre a produtividade da figueira. A concentração de B na solução do solo é geralmente controlada pelas reações de adsorção do boro, sendo que as plantas respondem somente ao B na solução do solo (GOLDBERG, 1997).

A matéria orgânica do solo adsorve (em base de peso) mais boro do que os constituintes minerais do solo (GOLDBERG, 1997). A complexação do boro pela matéria orgânica pode se dar com a formação de complexos boro-diol resultantes da quebra de componentes da matéria orgânica ou da ligação a grupos do ácido a-hidroxi carboxílico da matéria orgânica (YERMIYAHO et al., 1988; GOLDBERG 1997).

\section{CONCLUSÕES}

A adubação com esterco bovino elevou a produtividade da figueira. Os teores de fósforo e potássio no solo aumentaram com a aplicação de esterco, mas o teor de alumínio foi reduzido. Com o aumento das doses de ácido bórico adicionadas ao solo, houve aumento linear nos teores de B disponível, extraído pelo método de água quente. Mesmo efeito foi observado sobre o teor foliar de boro. Teores de B no solo de até $2,03 \mathrm{mg} \mathrm{dm}^{-3}$ não influenciaram a produtividade da figueira.

\section{REFERÊNCIAS}

BAYER, C.; MIELNICZUK, J. Dinâmica e função da matéria orgânica. In: SANTOS, G.A.; CAMARGO, F.A.O. Fundamentos da matéria orgânica do solo. Porto Alegre: Gênesis, 1999. p.9-26.

BORGES, A.L. et al. Adubação nitrogenada para bananeira "terra" (Musa sp. AAB, subgrupo Terra). Revista Brasileira de Fruticultura, Jaboticabal, v.24, p.189-193, 2002.

CAKMAK, I.; RÖMHELD, V. Boron deficiency-induced impairments of celular functions in plants. Plant and Soil, Netherlands, v.193, p.121-123, 1997.

CAMPO-DALL'ORTO F.A. et al. Frutíferas: frutas de clima temperado, II. In: RAIJ, B.V. et al. Recomendações de adubação e calagem para o Estado de São Paulo. Campinas: Instituto Agronômico, 1996. p.141-142. (Boletim Técnico 100).

CANELLAS, L.P. et al. Reações da matéria orgânica. In: SANTOS, G.A.; CAMARGO, F.A.O. Fundamentos da matéria orgânica do solo. Porto Alegre: Gênesis, 1999. p.69-89.

CORREA, A.E. et al. Aplicação de boro no solo e respostas do cafeeiro. Pesquisa Agropecuária Brasileira, Brasília, v.20, n.2, p.177-181, 1985.

FRANCHINI, J.C. et al. Alterações químicas em solos ácidos após a aplicação de resíduos vegetais. Revista Brasileira de Ciência do Solo, Viçosa, v.23, p.533-542, 1999.

FREIRE, L.R.; ALMEIDA, D.L. Recomendações de nutrientes. In: DE-POLLI, H. et al. (Coord). Manual de adubação para o Estado do Rio de Janeiro. Itaguaí: Universidade Rural, 1988. p.81-89.

GOLDBERG, S. Reactions of boron with soils. Plant and Soil, Dordrecht, v.193, p.35-48, 1997.

HOLANDA, J.J. et al. Utilização de esterco e adubo mineral em quatro seqüências de culturas em solo de encosta basáltica do Rio Grande do Sul. Revista Brasileira de Ciência do Solo, Viçosa, v.6, p.47-51, 1982. 
LOPES, A.S.; ABREU, C.A. Manejo da fertilidade do solo. Informe Agropecuário, Belo Horizonte, v.13, p.3-21, 1987.

MELLO, S.C.; VITTI, G.C. Influência de materiais orgânicos no desenvolvimento do tomateiro e nas propriedades químicas do solo em ambiente protegido. Horticultura Brasileira, Brasília, v.20, p.452-458, 2002.

MIYAZAWA, M. et al. Efeito de material vegetal na acidez do solo. Revista Brasileira de Ciência do Solo, Viçosa, v.17, p.411-416, 1993.

MIYAZAWA, M. et al. Neutralização da acidez do perfil do solo por resíduos vegetais. Informações Agronômicas, Piracicaba, v.92, p.1-8, 2000.

NAKAYAMA, L.H.I. Influência de doses de boro e zinco no desenvolvimento e nutrição mineral do cacaueiro. Agrotrópica, Ilhéus, v.1, p.34-38, 1989

NOBLE, M.E. et al. Better crops with plant food. Norcross, v.77, p.3-5, 1993.
OLIVEIRA FILHO, J.M. et al. Matéria orgânica do solo. Informe Agropecuário, Belo Horizonte, v.13, p.22-36, 1987.

QUAGGIO J.A. et al. Frutíferas: amostragem de folhas e diagnose foliar: In: RAIJ, B.V. et al. Recomendações de adubação e calagem para o Estado de São Paulo. Campinas: Instituto Agronômico, 1996. p.123-125. (Boletim Técnico, 100).

QUAGGIO J.A.; PIZA JR., C.T. Frutíferas tropicais. In: FERREIRA, M.E. et al. Micronutrientes e elementos tóxicos na agricultura. Jaboticabal: CNPq/FAPESP/ POTAFOS, 2001. p.458-491.

YAMADA, T. Matéria orgânica e boro controlariam o amarelinho dos citros? Informações Agronômicas, Piracicaba, v.93, p.1-1, 2001

YERMIYAHU, U. et al. Boron sorption on composted organic matter. Soil Science Society American Journal, v.52, p.1309-1313, 1998. 